\title{
Effect of the increasing use of coronary angioplasty on outcome at one year in patients with unstable angina
}

\author{
Stefano De Servi, Paolo Valentini, Luigi Angoli, Ezio Bramucci, Paolo Barberis, \\ Giuseppe Mariani, Giuseppe Specchia
}

\begin{abstract}
Objective-To determine whether the increasing use of percutaneous transluminal angioplasty in patients with unstable angina has reduced the need for bypass surgery and whether this change in the choice of treatment affected the outcome at one year in patients with unstable angina who were admitted to hospital in two different periods of time. Design-Retrospective analysis of consecutive patients with unstable angina (angina at rest with ST-T changes during pain) who underwent coronary arteriography in two different periods of time.

Patients-158 patients were admitted to hospital between January 1988 and June 1989 (group 1) and 140 patients admitted between January 1992 and June 1993 (group 2).
\end{abstract}

Results-Coronary angioplasty procedures nearly doubled from $29 \%$ in group 1 to $56 \%$ in group 2 whereas bypass surgery decreased from $36 \%$ in group 1 to $23 \%$ in group $2(P<0.01)$. Coronary angioplasty increased and bypass surgery decreased in patients with one vessel disease $(P<0.01)$, two vessel disease $(P<0.05)$, and three vessel disease $(P<$ 0.01). Coronary angioplasty also increased and bypass surgery decreased in refractory angina and in patients with ejection fraction $<0.50$ (both $P<0.05$ ). At 1 -year follow up, 14 patients in group 1 $(9 \%)$ and 10 in group $2(7 \%)$ either died or had myocardial infarction $(P=N S)$. Revascularisation procedures were needed in 16 group 1 patients $(10 \%)$ and 27 group 2 patients $(19 \%, P<0.05)$.

Conclusions-Coronary angioplasty became more widely used in patients with unstable angina. This reduced the need for bypass surgery in patients with multivessel disease, refractory angina, and depressed left ventricular function. This change in treatment did not affect 1-year mortality or the myocardial infarction rate. More patients in the more recent group in which angioplasty was the preferred treatment required a further revascularisation procedure than in the earlier group in which bypass grafting was more often used as the initial treatment.
(Br Heart F 1995;74:680-684)

Keywords: outcome; unstable angina; coronary angioplasty; bypass grafting

Percutaneous transluminal coronary angioplasty (PTCA) is accepted as a form of revascularisation in patients with unstable angina, ${ }^{1-7}$ but it is not known whether the growth of such procedures has affected the type of treatment in this group and in particular whether it has reduced the need for bypass surgery. Moreover, if the treatment strategy really has changed, has it affected outcome? We compared the choice of treatment for patients with unstable angina admitted to hospital in two different periods and compared the results of 1 -year follow up in these two groups.

Patients and methods

This is a retrospective analysis of consecutive patients with unstable angina who underwent coronary arteriography in two different periods: 158 patients were admitted to hospital between January 1988 and June 1989 (group 1) and 140 patients were studied between January 1992 and June 1993 (group 2). These two periods were selected to compare the latest experience (allowing for a 1-year follow up) with earlier experience at a time when coronary angioplasty was beginning to be recognised as a successful treatment in patients with unstable angina. ${ }^{8}$ Unstable angina was defined as chest pain occurring at rest and accompanied by transient ST-T changes on the electrocardiogram (that is, ST segment elevation or depression of $>1 \mathrm{~mm}, 0.08$ seconds after the $\mathrm{J}$ point). ${ }^{9} 10$ These patients represent a high-risk subset. ${ }^{11-15}$ The presenting symptoms were classified as follows: (a) new onset angina-rest angina developing within 2 months before coronary angioplasty; $(b)$ crescendo angina ${ }^{16}$ worsening of patient's previous exertional angina that included angina at rest over the preceding 2 months; (c) early post-infarction angina ${ }^{17}$-angina at rest occurring within 15 days after a myocardial infarction; $(d)$ plain rest angina-angina at rest that developed $>2$ months before coronary angiography in patients without history of exertional angina or recent myocardial infarction. Patients who had already had coronary angioplasty were excluded from the study.
Dr S De Servi, Divisione di Cardiologia, Policlinico S. Accepted for publication 12 June 1995 

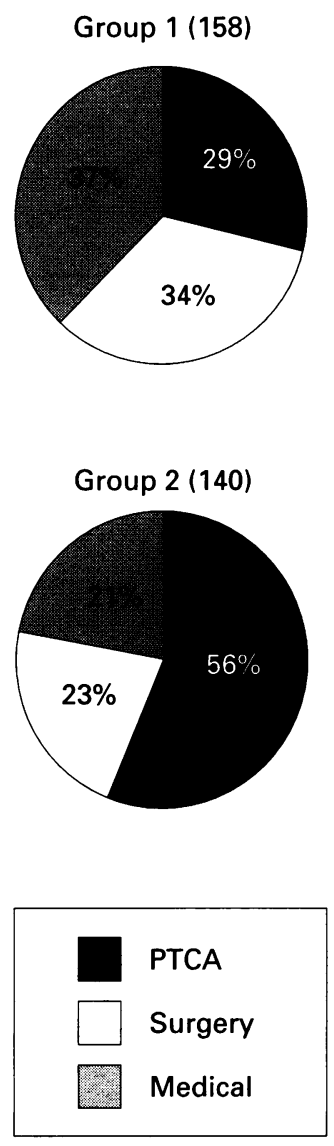

Figure 1 Choice of treatment in the two groups of patients. PTCA procedures increased from $29 \%$ in group 1 to $56 \%$ in group 2 , whereas bypass surgery decreased from $34 \%$ in group 1 to $23 \%$ in group 2.
All patients were treated with $\beta$ blockers (generally metoprolol $50-100 \mathrm{mg}$ twice a day), calcium antagonists (generally nifedipine $10-20 \mathrm{mg}$ three times a day or diltiazem 60-120 mg three times a day) and oral nitrates (usually isosorbide mononitrate $20-40 \mathrm{mg}$ three times a day). Heparin was given intravenously or subcutaneously to maintain the partial thromboplastin time (aPTT) at twice baseline. All patients were given aspirin (325 mg/day). Refractory angina was defined as recurrent chest pain at rest with ST-T changes despite antianginal treatment.

\section{CORONARY ARTERIOGRAPHY}

Selective coronary arteriography was performed in multiple projections by the Sones or Judkins technique after premedication with $10 \mathrm{mg}$ of diazepam. Significant stenosis was defined as diameter narrowing of $>50 \%$ in at least one coronary artery. Patients were classified as having one, two, or three vessel disease according to the number of vessels with significant coronary stenoses. The ejection fraction was calculated from left ventriculograms performed in $30^{\circ}$ right anterior oblique projection.

\section{PERCUTANEOUS TRANSLUMINAL CORONARY} ANGIOPLASTY (PTCA)

Intense effort were made to stabilise patients before PTCA. The interval between the last episode of chest pain and the procedure was $4 \cdot 8$ days (range $0-15$ ) in group 1 and $4 \cdot 2$ days (range $0-13$ ) in group 2. PTCA procedures were performed using over the wire or monorail catheter systems with low-profile dilatation balloons. At the beginning of the procedure an intravenous bolus injection of $10000 \mathrm{UI}$ of heparin was given, followed by a bolus of 5000 $\mathrm{UI} / \mathrm{h}$ of elapsed time during the procedure. In most patients with multivessel disease only the

Table 1 Clinical characteristics of the two groups

\begin{tabular}{lll}
\hline Characteristic & $\begin{array}{l}\text { Group 1 } \\
(n=158)(\%)\end{array}$ & $\begin{array}{l}\text { Group 2 } \\
(n=140)(\%)\end{array}$ \\
\hline Male sex & $134(85 \%)$ & $119(85 \%)$ \\
Age & $56($ range 19-72) & $59($ range 18-90) \\
Hypertension & $58(37)$ & $39(28)$ \\
Diabetes & $17(11)$ & $21(15)$ \\
Previous MI & $75(45)$ & $65(46)$ \\
Previous CABG & $8(5)$ & $14(10)$ \\
$\uparrow$ ST during pain & $76(48)$ & $45(32)$ \\
\ST during pain & $82(52)$ & $95(68)$ \\
Recent onset angina & $43(27)$ & $35(25)$ \\
Crescendo angina & $43(27)$ & $34(24)$ \\
Early PI angina & $23(15)$ & $16(12)$ \\
Plain rest angina & $49(31)$ & $55(39)$ \\
\hline
\end{tabular}

$\uparrow S T$, ST segment elevation; $\downarrow$ ST, ST segment depression; PI, post infarction; MI, myocardial infarction, CABG, coronary artery bypass grafting.

Table 2 Angiographic characteristics of the two groups

\begin{tabular}{lll}
\hline Characteristic & $\begin{array}{l}\text { Group 1 } \\
(n=158)(\%)\end{array}$ & $\begin{array}{l}\text { Group 2 } \\
(n=140)(\%)\end{array}$ \\
\hline Mean EF & $0 \cdot 6$ (range $0 \cdot 31-0 \cdot 78)$ & $0 \cdot 61$ (range $0 \cdot 20-0 \cdot 80)$ \\
EF < 0.50 & $30(19)$ & $21(15)$ \\
NS CAD & $13(8)$ & $8(6)$ \\
1 Vessel & $55(35)$ & $44(31)$ \\
2 Vessel & $49(31)$ & $40(29)$ \\
3 Vessel & $41(26)$ & $48(34)$ \\
\hline
\end{tabular}

$\mathrm{EF}$, ejection fraction.

NS CAD, non-significant coronary artery disease. ischaemia-related vessel, identified on the basis of electrocardiographic and angiographic findings, was dilated. ${ }^{18}$ Success was defined as a final reduction in luminal diameter by $\geqslant 20 \%$ to a residual narrowing of $<50 \%$ with no major complications (death, non-fatal myocardial infarction, sustained acute coronary occlusion, emergency coronary bypass surgery). ${ }^{8}$

FOLLOW UP AND STATISTICAL ANALYSIS

One-year follow up data were obtained from telephone interviews or visits. We compared demograpic, clinical, and angiographic data in the two groups using Student's $t$ test, Chi squared, or Fisher's exact test when appropriate. One year cardiac events (cardiac death, acute myocardial infarction, new admissions to hospital for cardiac reasons, and new revascularisation procedures) in the two groups were evaluated with the log-rank test.

\section{Results}

CLINICAL AND ANGIOGRAPHIC FINDINGS

The clinical and angiographic characteristics of the two groups were substantially similar (table 1 and 2 ). The only statistically significant difference $(P<0.01)$ was that in group 2 more patients had transient ST depression than had ST elevation during pain $(68 \% v$ $32 \%$ ) whereas in group 1 the types of ST-segment shifts were equally common $(52 \% v 48 \%)$. However, there was no difference in the clinical presentation of unstable angina in the two groups. One vessel and two vessel disease were found in about one third of patients in the two periods. Triple vessel or left main disease was more common in group 2 than in group $1(34 \% v 26 \%)$ but the difference was not statistically significant.

TREATMENT CHOICE

In group 1, 46 patients $(29 \%)$ underwent PTCA, 53 (34\%) bypass surgery, and 59 (37\%) has continued medical treatment (fig 1). In group 2,78 patients $(56 \%)$ underwent PTCA, $32(23 \%)$ bypass surgery, and 30 $(21 \%)$ had continued medical treatment $(P<0.01)$. Table 3 shows the choice of treatment according to extent of coronary artery disease. From the first to the second period there was a significant increase in PTCA procedures and a decrease in bypass surgery in single vessel disease $(P<0.01)$, two vessel disease $(P<0.05)$, and three vessel disease $(P<0.01$ ) (fig 2 ). In patients with refractory angina, PTCA procedures increased from $43 \%$ in group 1 to $63 \%$ in group 2, whereas bypass surgery decreased from $39 \%$ in group 1 to $22 \%$ in group $2(P<0.05)$. Among patients with ejection fraction $<0.50$, PTCA procedures also increased and surgery decreased from group 1 (PTCA $10 \%$, surgery 53\%) to group 2 (PTCA $33 \%$, surgery $33 \%, \mathrm{p}<0.05$ ).

\section{PTCA PROCEDURES}

Table 4 shows the results of the procedures in the two periods. Procedures were successful in $91 \%$ of group 1 patients and in $91 \%$ of group 2 
Table 3 Treatment choice in the two groups in patients with clinically significant coronary disease

\begin{tabular}{|c|c|c|c|c|c|c|}
\hline & \multicolumn{2}{|l|}{$P T C A$} & \multicolumn{2}{|l|}{ Bypass } & \multicolumn{2}{|c|}{ Medical treatment } \\
\hline & $\begin{array}{l}\text { Group 1 } \\
(n=46)\end{array}$ & $\begin{array}{l}\text { Group 2 } \\
(n=78)\end{array}$ & $\begin{array}{l}\text { Group } 1 \\
(n=53)\end{array}$ & $\begin{array}{l}\text { Group 2 } \\
(n=32)\end{array}$ & $\begin{array}{l}\text { Group 1 } \\
(n=46)\end{array}$ & $\begin{array}{l}\text { Group 2 } \\
(n=22)\end{array}$ \\
\hline $\begin{array}{l}1 \text { Vessel disease } \\
2 \text { Vessel disease† } \\
3 \text { Vessel disease }\end{array}$ & $\begin{array}{r}30 \\
15 \\
1\end{array}$ & $\begin{array}{l}42 \\
23 \\
13\end{array}$ & $\begin{array}{r}6 \\
12 \\
35\end{array}$ & $\begin{array}{r}0 \\
10 \\
22\end{array}$ & $\begin{array}{r}19 \\
22 \\
5\end{array}$ & $\begin{array}{c}2 \\
7 \\
13\end{array}$ \\
\hline
\end{tabular}

patients. A complete revascularisation procedure was accomplished in two of the 16 patients with multivessel disease in group 1 $(12.5 \%)$ and in seven of the 36 patients with multivessel disease in group $2(19 \%)(P=$ NS). There were no deaths in the two groups. The myocardial infarction rate was low in both periods $(2 \cdot 2 \%$ in group 1 and $2 \cdot 6 \%$ in group $2)$. Urgent revascularisation was necessary in $2 \cdot 2 \%$ of patients in group 1 and in no patients of group 2. Coronary stents were implanted in for bailout procedures in four patients $(5 \%)$ in group 2.

Figure 2 Choice of treatment in the two groups according to the extent of coronary disease. The incidence of PTCA procedures increased, whereas bypass surgery decreased in all subgroups, irrespective of the number of diseased coronary vessles.
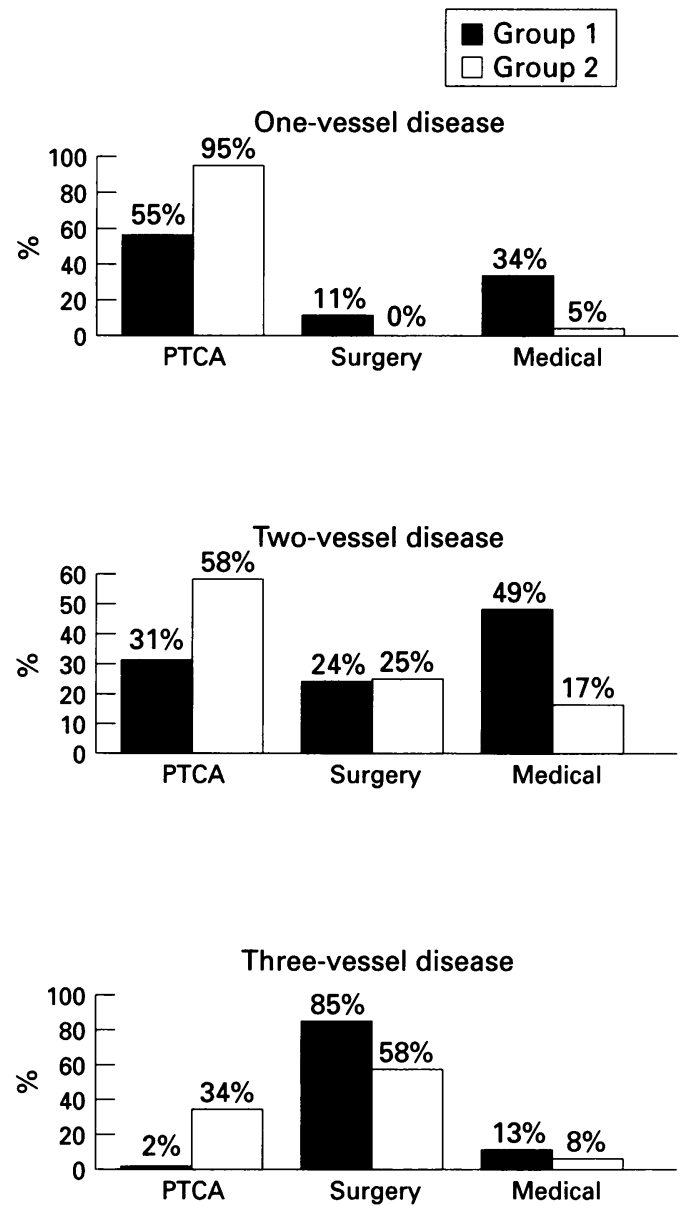

Table 4 Results of coronary angioplasty in the two groups

\begin{tabular}{lll}
\hline Result & $\begin{array}{l}\text { Group 1 } \\
(n=46)(\%)\end{array}$ & $\begin{array}{l}\text { Group 2 } \\
(n=78)(\%)\end{array}$ \\
\hline Success rate & 91 & 91 \\
Death & 0 & 0 \\
Acute MI & $2 \cdot 2$ & $2 \cdot 6$ \\
Urgent bypass & $2 \cdot 2$ & 0 \\
Stent & 0 & 5 \\
\hline
\end{tabular}

FOLLOW UP

After a year, six patients (4\%) in group 1 had died (four had bypass surgery, one PTCA, and one was on medical treatment). Thirty patients $(19 \%)$ had new admissions to hospital for cardiac reasons (eight had surgery, 11 had been treated with PTCA, and 11 were on medical treatment). Myocardial infarction occurred in eight patients $(5 \%)$. Six patients (4\%) needed bypass surgery (four were on medical treatment and two had been treated with PTCA) and 10 underwent PTCA (two had been treated with surgery, five with PTCA, and three had been discharged on medical treatment).

In group 2 , one patient $(0.7 \%)$ died before scheduled surgery. Admissions to hospital for cardiac reasons occurred in 39 patients $(28 \%)$ : six had been treated with surgery, 25 with PTCA, and eight medically. Myocardial infarction occurred in nine patients $(6 \%)$. There was no difference in one year survival or myocardial infarction rate between group 1 and group 2 . Thirteen patients $(9 \%)$ had bypass surgery (seven were on medical treatment and six had previously been treated with PTCA) and $14(10 \%)$ had a new PTCA procedure (all had previously been treated with PTCA). Therefore new revascularisation procedures occurred in 16 group 1 patients $(10 \%)$ and in 27 group 2 patients $(19 \%$, $\mathrm{P}<0.05)$.

\section{Discussion}

Patients with angina at rest associated with transient ST-T changes are a high-risk subgroup of those with unstable angina. ${ }^{1115}$ Olson et al found that after an average follow up of about 25 months, an ischaemic ECG during angina was associated with $40 \%$ probability of death or of acute myocardial infarction, whereas patients without ischaemic ECG changes had a $13 \%$ indicence of such unfavourable events. ${ }^{12}$ Cohen $e t a l$, in a study of 90 patients, found that ST segment changes during pain were a reliable predictor of adverse clinical events (recurrent ischaemia, infarction or need of revascularisation). ${ }^{15}$ In that study the positive predictive value for clinical events of ST deviation $>1 \mathrm{~mm}$ in at least 2 leads was $89 \%$. For these reasons, early coronary angiography and revascularisation procedures without delay have been advocated in this high-risk population. ${ }^{18}$ In the present study, the relative impact of PTCA and bypass surgery in such patients was retrospectively analysed and compared in two different periods. The data show that over the last 
years, there has been an increase in angioplasy procedures, which nearly doubled from $29 \%$ in the early period to $56 \%$ in the late period. Concomitantly, bypass surgery was performed in fewer patients $(36 \%$ in group 1 and $23 \%$ in group 2). The growth of PTCA was significant both in patients with single vessel disease and multivessel disease. In group 2 nearly all patients with single vessel disease had PTCA (95\%): in group 1 the comparable figure was $55 \%$ (fig 2). The proportion of patients discharged on medical treatment dropped from $35 \%$ and $5 \%$ and, those given surgical treatment from $11 \%$ in group 1 to $0 \%$ in group 2 . In patients with multivessel disease, surgical treatment declined from $52 \%$ in group 1 to $36 \%$ in group 2, whereas PTCA increased from $18 \%$ in group 1 to $41 \%$ in group 2 . This shift in treatment strategy reflects, on one hand, the greater experience of operators who have lately attempted lesions with complex morphology that they would not have attempted in previous years and, on the other hand, a better logistic organisation that allows us to perform PTCA immediately after diagnostic coronary arteriography, thus reducing the patient's hospital stay. These observations are supported by the analysis of treatment choice in very high-risk subsets, such as in patients with refractory angina and in those with depressed left ventricular function. In both clinical conditions, there was a significant increase in angioplasty procedures over bypass surgery in the late experience as compared with the early one.

The change in treatment strategy did not affect one year survival in this population. The occurrence of major clinical events was similar, though mortality in group 2 patients tended to be lower. However, in group 2 patients there was a significantly higher incidence of new revascularisation procedures during the follow up period. These data accord with the results of recent randomised trials comparing the long-term effects of PTCA and bypass grafting, ${ }^{19-22}$ which showed a similar long-term survival rate with both treatments, but more new revascularisation procedures in the PTCA group than in the surgical group. It is interesting to note that in the German Angioplasty Bypass Investigation $^{20}$ the cumulative risk of death or myocardial infarction from the time of randomisation was higher in the surgically treated patients than in the PTCA group. The fact that most clinical events occurred in the waiting period before the scheduled operation, underlines the need for revascularisation procedures to be carried out without delay, particularly in patients with severe ischaemic heart disease. This, together with the shorter hospital stay in patients undergoing PTCA $^{20}$ favours the choice of PTCA rather than bypass surgery for revascularising patients with high risk unstable angina.

In our study, PTCA was performed in $41 \%$ of group 2 patients with multivessel disease, a higher proportion than that reported in the Emory Angioplasty Surgery Trial for patients deemed to be eligible for both PTCA and bypass surgery. ${ }^{23}$ In most patients with unstable angina and multivessel disease, however, there is a "culprit lesion" in one vessel that is thought to be responsible for the instability. ${ }^{4518}$ This may explain the high proportion of patients with multivessel disease in our study who had PTCA and the low proportion who had complete revascularisation procedures $(12 \%$ in group 1 and $19 \%$ in group 2).

The PTCA success rate in both periods (91\%) compares favourably with that reported in earlier series. ${ }^{4-8}$ Our strategy of stabilising symptoms before PTCA probably reduced the procedure-related complications. Stammen et al, who used a conservative approach and delayed PTCA in 631 patients reported equally good results of PTCA in unstable angina. ${ }^{24}$ Moreover, in a recent study, Myler et al found that a more aggressive approach to PTCA was associated with a lower success rate and higher complication rate than a strategy of delay. ${ }^{25}$ In our second study period no patient needed urgent bypass surgery because acute occlusions during or immediately after PTCA were successfully managed with stent implantation, a circumstance that occurred in $5 \%$ of cases. ${ }^{26} 27$

In conclusion, these data show that in recent years PTCA has become the first treatment in patients with unstable angina. This has reduced the need for bypass surgery in patients with multivessel disease, refractory angina, and depressed left ventricular function. This change in treatment strategy did not affect 1 year mortality or the myocardial infarction rate, but the need of revascularisation procedures increased in the follow up period.

1 de Feyter PJ, Serruys PW. Percutaneous transluminal coronary angioplasty for unstable angina. In: Topol EJ, ed. Textbook of interventional cardiology. Philadelphia WB Saunders, 1992;274-8.

2 Sharma B, Wyeth R, Kolath GS, Gimenez HJ, Franciosa JA. Percutaneous transluminal coronary angioplasty of one vessel for refractory unstable angina: Efficacy in single and multivessel disease. Br Heart $f$ 1988;59. $280-6$.

3 Plokker H, Ernst S, Bal E, et al. Percutaneous transluminal coronary angioplasty in patients with unstable angina pectoris refractory to medical therapy: Long term clinical and angigraphic results. Cathet Cardiovasc Diagn 1988;

4 de Feyter PJ. Coronary angioplasty for unstable angina. $\mathrm{Am}$ Heart $\mathcal{F}$ 1989;118:860-8.

5 Wohlgelertner D, Clenan M, Highman HA, Zaret BI Pecutaneous transluminal coronary angioplasty of the "culprit" lesion for management of unstable angina pectoris in patients with multivessel coronary artery disease. Am F Cardiol 1986;58:460-4.

6 Williams D, Raley R, Singh A, Gewirtz H, Most A. Evaluation of the role of coronary angioplasty in patient with unstable angina pectoris. Am Heart $\mathcal{f} 1981 ; 102$ 1-9.

7 Meyer J, Schmitz H, Kiesslich T, et al. Percutaneous transluminal coronary angioplasty in patients with stable and Heart $\mathcal{f} 1983 ; 106: 973-80$.

8 Bentivoglio LG, Detre K, Yeh WL, Williams DO, Kelsey $\mathrm{SF}$, Faxon DP. Outcome of percutaneous transluminal coronary pectoris. $\mathcal{F}$ Am Coll Cardiol 1994;24:1195-206.

9 Langer A, Freeman MR, Armstrong PW. ST Segment shift in unstable angina: Pathophysiology and association in unstable angina: Pathophysiology and association with coronary anatomy and

10 De Servi S, Ghio S, Ferrario M, et al. Clinical and angiographic findings in angina at rest. Am Heart $\mathcal{F} 1986$; 111:6-11.

11 Braunwald E, Jones RH, Mark DB, et al. Diagnosing and managing unstable angina. Circulation 1994;90: 
12 Olson HG, Lyons KP, Aronow WS, Stinson PJ, Kuperus J, Waters HJ. The high-risk angina patient: Identification by clinical features, hospital course, electrocardiography and technetium-99m stannous pyrophosphate scintigraphy. Circulation 1981;64:674-84.

13 Betriu A, Heras $M$, Cohen $M$, Fuster V. Unstable angina: Outcome according to clinical presentation. $₹ \mathrm{Am}$ Coll Outcome according to cliniol
Cardio92;19:1659-63.

14 Gazes PC, Mombley EM, Faris HM, Duncan RC, Humphries GB. Preinfarctional (unstable) angina: A prospective study: Ten year follow up. Circulation 1973 48:331-7

15 Cohen M, Hawkins L, Greenberg S, Fuster V. Usefulness of ST-Segment changes in $>2$ leads on the emergency room electrocardiogram in either unstable angina pectoris or non-Q wave myocardial infarction in predicting outcome. Am f Cardiol 1991;67:1368-76.

16 De Servi S, Ghio S, Ardissino D, et al. Management of crescendo angina. Eur Heart 7 1985;6(suppl F):83-6.

17 De Servi S, Vaccari L, Graziano G, et al. Clinical and angiographic data in early post-infarction angina. Eur Heart $₹ 1986$; 7 (suppl C):69-72.

18 de Feyter PJ, Serruys PW, van der Brand M, et al. Emergency coronary angioplasty in refractory unstable Emergency coronary angioplasty in 1 angina. $N$ Engl $\Im$ Med 1985;313:342-6.
ang

19 King III SB, Lembo NJ, Weintraub WS, et al. A randomized trial comparing coronary angioplasty with coronary bypass surgery. $N$ Engl $f$ Med 1994;331. 1044-50.
20 Hamm CW, Reimers J, Ischinger T, Rupprecht H-J, Berger J, Bleifeld W. A randomized study of cornary angioplasty compared with bypass surgery in patients with symptomatic multivessel coronary disease. $N$ Engl $f$ Med 1994;331:1037-43.

Med 1994;331:1037-43.
RITA Trial Participants. Coronary angioplasty versus coronary artery bypass surgery: The Randomized Intervention Treatment of Angina (RITA) trial. Lancet 1993;341:573-80.

22 BARI, CABRI, EAST, GABI and RITA. Coronary angioplasty on trial. Lancet 1990;335:1315-6.

23 King SB III, Lembo NJ, Weintraub WS, et al. A randomized trial comparing coronary angioplasty with coronary bypass surgery. $N$ Engl $f$ Med 1994;331: 1044-50.

24 Stammen F, De Scheerder I, Glazier JJ, et al. Immediate and follow-up results of the conservative coronary angioplasty strategy for unstable angina pectoris. Am f Cardiol 1992;69:1533-7.

25 Myler RK, Shaw RE, Stertzer SH, et al. Unstable angina and coronary angioplasty. Circulation 1990;82(suppl II): 88-95.

26 Sigwart U, Urban P, Golf S, et al. Emergency stenting for acute occlusion after coronary balloon angioplasty. Circulation 1988;78:1121-7.

27 Herrmann HC, Buchbinder M, Clemen MW, et al. Emergency use of balloon-expandable coronary artery stenting for failed percutaneous transluminal coronary angioplasty. Circulation 1992;86:812-9. 